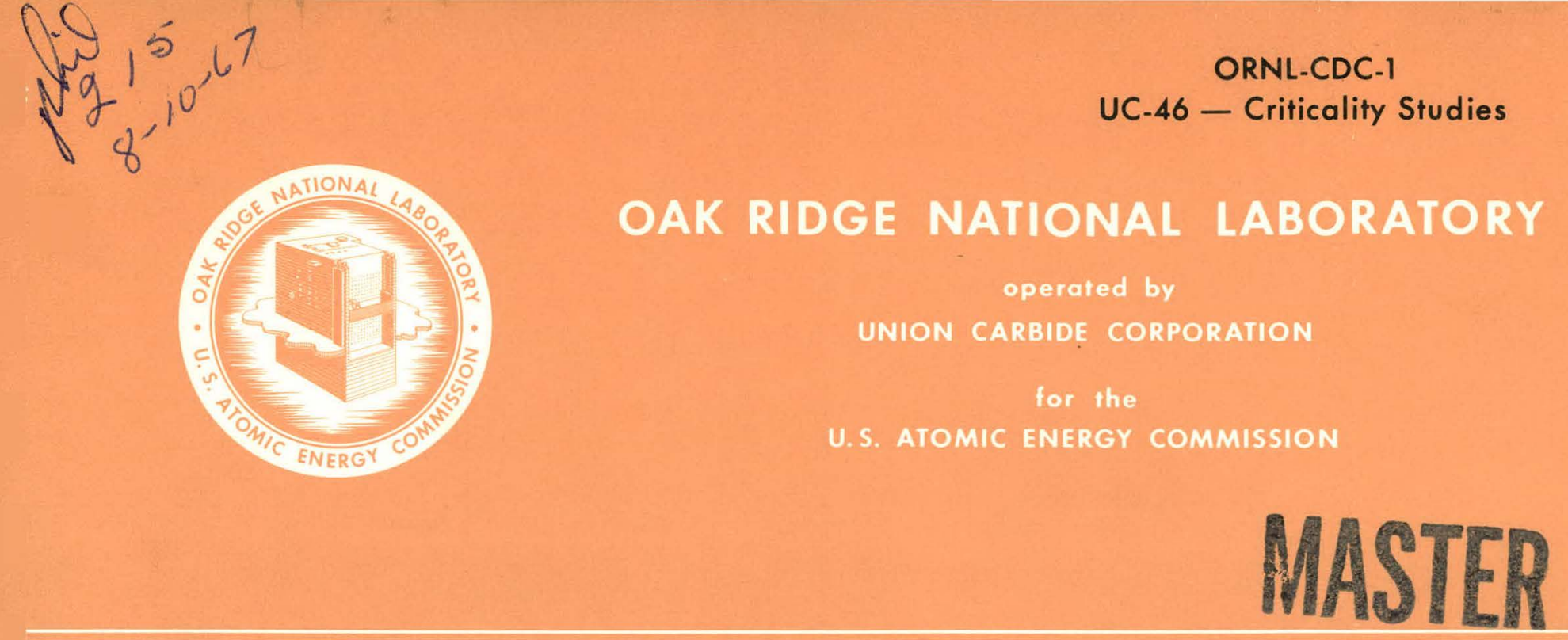

\title{
CRITICALITY OF LARGE SYSTEMS OF SUBCRITICAL U(93) COMPONENTS
}

\author{
J. T. Thomas
}

Oak Ridge National Laboratory

\section{CRITICALITY DATA CENTER}




\section{DISCLAIMER}

This report was prepared as an account of work sponsored by an agency of the United States Government. Neither the United States Government nor any agency Thereof, nor any of their employees, makes any warranty, express or implied, or assumes any legal liability or responsibility for the accuracy, completeness, or usefulness of any information, apparatus, product, or process disclosed, or represents that its use would not infringe privately owned rights. Reference herein to any specific commercial product, process, or service by trade name, trademark, manufacturer, or otherwise does not necessarily constitute or imply its endorsement, recommendation, or favoring by the United States Government or any agency thereof. The views and opinions of authors expressed herein do not necessarily state or reflect those of the United States Government or any agency thereof. 


\section{DISCLAIMER}

Portions of this document may be illegible in electronic image products. Images are produced from the best available original document. 
Printed in the United States of America. Available from Clearinghouse for Federal Scientific and Technical Information, National Bureau of Standards,

U.S. Department of Commerce, Springfield, Virginia 22151

Price: Printed Copy $\$ 3.00$; Microfiche $\$ 0.65$

\section{LEGAL NOTICE}

This report was prepared as an account of Government sponsored work. Neither the United States, nor the Commission, nor any person acting on behalf of the Commission:

A. Makes any warranty or representation, expressed or implied, with respect to the accuracy, completeness, or usefulness of the information contained in this report, or that the use of any information, apparatus, method, or process disclosed in this report may not infringe privately owned rights; or

B. Assumes any liabilities with respect to the use 'fy, or for damages resulting from the use of any information, apparatus, method, or process disclosed in this report.

As used in the above, "person acting on behalf of the Commission" includes any employee or contractor of the Commission, or employee of such contractor, to the extent that such employee or contractor of the Commission, or employee of such contractor prepares, disseminates, or provides access to, any information pursuant to his employment or contract with the Commission, or his employment with such contractor. 
ORNL-CDC-1

UC-46 Criticality Studies

\section{CFSTI PMIC}

H. . $\$ 3.00 ; .65$

CRITICALITY OF

LARGE SYSTEMS OF SUBCRITICAL U(93) COMPONENTS

J. T. Thomas

Neutron Physics Division

Oak Ridge National Laboratory

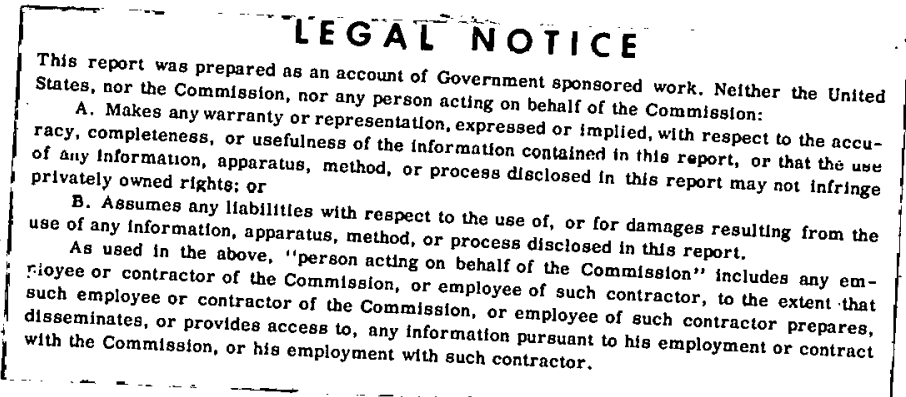

\section{AUGUST 1967}

\section{OAK RIDGE NATIONAL IABBORATORY \\ Oak Ridge, Tennessee \\ operated by \\ UNION CARBIDE CORPORATION}

for the

U. S. ATOMIC ENERGY COMMISSION

Contract No. W-7405-eng-26 
THIS PAGE

\section{WAS INTENTIONALLY \\ LEFT BLANK}


FOR E WOR D

The Criticality Data Center has been established at the Oak Ridge National Laboratory under the auspices of the U. S. Atomic Energy Commission for the development of methods allowing extension and application of data derived from experiments and from analyses to problems in nuclear criticality safety, as well as for the review and evaluation of the data themselves. A necessary part of this program is a medium whereby information germane to the intent of the Center is made available. This report is the first in the series inaugurated for that purpose. 
THIS PAGE

\section{WAS INTENTIONALLY}

LEFT BLANK 


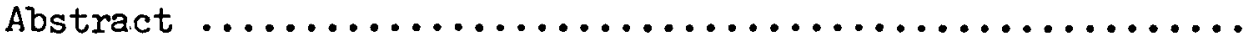

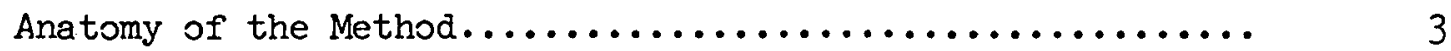

Unreflected sys tems.......................... 5

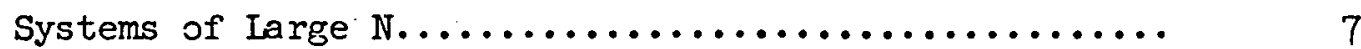

Density Analogue Representation.................. 12

Paraffin Reflected Systems..................... 21

Reflected Systems of Large N........................ 25 Density Analogue Representation with Reflector Present. 28

Factors for Reflection......................... 28

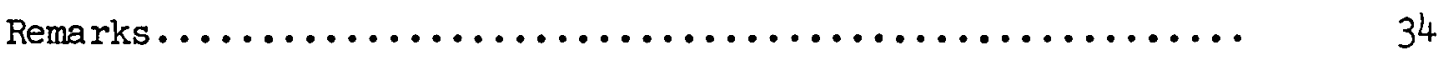

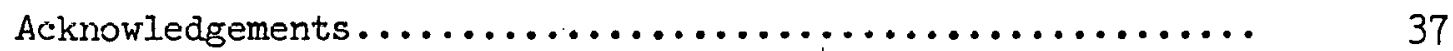




\title{
CRITICALITY OF \\ IAARE SYSTEMS OF SUBCRITICAL U(93) COMPONENTS
}

J. T. Thomas

\begin{abstract}
Methods for estimating the number of components required for criticality of unreflected and paraffin reflected systems of subcritical units are described. A neutron nonleakage fraction parameter is defined and leads to a correlation confirmed to within $5 \%$ of the number of units by comparison with experimental data for three dimensional cuboidal arrays. A density analogue representation of the arrays is readily derivable and is shown to approximate the results from the above method, but is less precise. Factors by which the number of units in an unreflected critical array is reduced by adding a paraffin reflector are found to range from about six to greater than 30 depending on the material and on the average uranium density considered. The methods are supported by Monte Carlo calculations demonstrated to be reliable by comparison with the results of critical experiments.
\end{abstract}




\section{INTRODUCTION}

Present regulations ${ }^{1}$ governing the storage and transport of fissile materials require the assessment of systems so large that experimental verification is often not practicable. This implies that judgement as to criticality - and hence, safety - is truly made on the credibility of the method of evaluation. It is not sufficient, therefore, only to check the method of estimation by experiments wherever possible, but there also should be an acceptable method for verifying extrapolations or criticality estimates that are far removed from experiments. The most likely manner to accomplish the latter is by means of detailed neutronics calculations such as are available in Monte Carlo techniques. A Monte Carlo search for criticality, however, can become an economic burden, especially if many areas are examined as in a parameter survey. It is feasible, however, to utilize a reliable Monte Carlo code to validate estimates of criticality made by semi-empirical methods which, in turn, are confirmed by the integral results of experiments.

In view of the large safety factors demanded by regulations in the specification of storage and transport, it seems reasonable that knowledge to within 5 or $10 \%$ of the number of components required to be critical at a given spacing is satisfactory.

The following presentation is intended to extend simple, well-known concepts applicable to individual critical units ${ }^{2}$ to critical arrays of subcritical components. The methods and their limits of application are described, are applied to components utilized in critical experiments, $2-4$ and are shown to yield estimates for configurations not studied experimentally. The estimates are validated by Monte Carlo calculations.

1. Regulations for the Safe Transport of Radioactive Materials, 1964 Revised Edition, International Atomic Energy Agency, Vienna (1965).

2. H. Ç Paxton et al., "Critical Dimensions of Systems Containing U235, $\mathrm{Pu}^{239}$, and $\mathrm{U}^{233}$," TID-7028, pp. 3-4 (June 1964).

3. J. T. Thomas, "Critical Three-Diemsnional Arrays of Neutron-Interacting Units," ORNL-TM-719 (October 1963).

4. J. T. Thomas, "Critical Three-Dimensional Arrays of Neutron-Interacting Units - Part II - U(93.2) Metal," ORNL-TM-868 (July 1964). 


\section{ANATOMY OF THE METHOD}

We begin by noting that interest lies in what can be said about the criticality of large assemblages of subcritical units of fissile materials. We confine our attention to systems of identical units. This simplification assures us of a single characteristic average neutron energy spectrum independent of the number of units present. The fate of neutrons in a critical system is such that there is a balance established between the rates of absorption, production, and leakage. Since the first two must take place within the fissile material of an array, it is clear that an adjustment of leakage rate must be made to maintain criticality as the number of units is changed. Further, in order to maintain the balance between the three processes the fraction of neutrons leaking must be independent of the number of pieces and the size of the system.

We assume, therefore, that we can approximate the array nonleakage fraction by a relation similar to $\left(1+\vec{M}^{2} B^{2}\right)^{-1}$, where $B^{2}$ is a geometric buckling and $\overrightarrow{\mathrm{M}}^{2}$ a suitable neutron-energy-averaged migration area. We shall use the quantity $\mathrm{NB}_{\mathrm{N}}^{2}$ to replace $\overrightarrow{\mathrm{M}}^{2} \mathrm{~B}^{2}$ in the expression, where $\mathrm{N}$ is the number of units in a system and $\mathrm{B}_{\mathrm{N}}^{2}$ the corresponding system geometric buckling. The number of units in a critical system, $N$, is known to vary inversely with the average uranium density of the system to some power, not necessarily to the second power as theory would require. The density dependence is the only property of $N$ that suggests its use as a coefficient of $B_{N}^{2}$. Further, the effects of non-uniformity, or lumping, of fissile material, unit size and unit shape variations on the usual nuclear parameters, which enter such a calculation, are not completely understood and we presume such changes are adequately approximated by the density exponent in some unknown way.

The correlations that follow are founded upon the two postulates

1. The fraction of neutrons that leak from different critical arrays of the same units is a constant, and

2. The nonleakage fraction is suitably represented by the expression $\left(1+\mathrm{NB}_{\mathrm{N}}^{2}\right)^{-1}$. 
Given two critical systems of identical units, one with $N$ and the other with $N^{\prime}$ units, we may write

$$
N B_{N}^{2}=N^{\prime} B_{N}^{2}
$$

and since $N$ and $N^{\prime}$ are arbitrary, it follows

$$
\mathrm{NB}_{N}^{2}=\text { constant }
$$

for arrays of the given unit. Equation (2) will, in all liklihood, subsist for any systematic method of computing the quantity $\mathrm{B}_{\mathrm{N}}^{2}$. The overall shape of the systems under consideration here wili be, in general, cuboidal and we may, for convenience, adopt the usual simple expression for the buckling of this geometry:

$$
B^{2}=\sum_{i=1}^{3} \frac{\pi^{2}}{\left[a_{i}+2 \lambda\right]^{2}}
$$

where $a_{i}$ are the three dimensions of the system and $\lambda$ is a suitable extrapolation distance. For systems of units we express $a_{i}$ in terms of the unit dimensions, $d_{i}$, their surface separation, $\delta$, and the number of units, $n_{i}$; along the ith direction, thusly,

$$
\mathrm{B}_{N}^{2}=\sum_{i=1}^{3} \frac{\pi^{2}}{\left[\mathrm{n}_{i}\left(d_{i}+\delta\right)+2 \lambda\right]^{2}}
$$

where

$$
\mathrm{N}=\prod_{i=1}^{3} \mathrm{n}_{i}
$$

It is readily apparent that if the constant in Eq. (2) is known, the dependence of the critical spacing, $\delta$, on the value of $\lambda$ diminishes as $N$ increases. Further, whenever experimental data exist for arrays of a given unit, it is possible to determine a suitable value of $\lambda$ and of the constant in Eq. (2). 


\section{UNREFLECTED SYSTEMS}

An effort to examine the behavior of $\mathrm{Eq}$. (2) is made in Table 1 where the results of a number of three-dimensional, unreflected critical systems of fissile materials have been collected and the constants $\mathrm{NB}_{\mathrm{N}}^{2}$ and $\lambda$ determined. For each case listed the value of $\lambda$ satisfying $\mathrm{Eq}$. (2) was sought. Considering the overall dimensions of the systems, the variation in $\lambda$ is not large. There also appears to be a dependence of $\lambda$ upon the units and on the array shape. For each entry in the Table the first column describes the critical assembly. The total number of units in an array is given as a subscript to the unit letter designation. The bracket, following the letter, contains the reflector thickness, zero in all cases; the unit surface separation; the corresponding average uranium density; and an array shape parameter, the ratio of the array height to the square root of its base area.

A description of an average unit in the array is contained in Columns 2-4. The number of units along the three edges of the array is given in Column 5. The value of $\lambda$ and the constant $\mathrm{NB}_{N}^{2}$ determined from Eq. (2) are given in Columns 6 and 7 , respectively.

The last column of Table 1 contains the multiplication factor for each of the arrays computed by the GEM-3 Monte Carlo code. 5 These same systems were computed earlier using the GEM-l code and the values of $\mathrm{k}$ were about $3 \%$ larger. The difference between the GEM-1 and GEM-3 results is due to a revision in the cross section sets used. The GEM code has been used to compute systems much more complex than those considered here. Its performance has been satisfactory ${ }^{6}$ under such major variations as unit shape and mass, array shape, array reflection by hydrogeneous materials, the presence of moderator and container materials, two extreme spectra, mixed spectra, and the ${ }^{235} U$ enrichment.

If we permit $k$ values as determined by reliable Monte carlo codes to be an acceptable substitute for experiment, then we have a credible means of evaluating systems not easily susceptible to experimental verification.

5. This code was furnished by the UKAEA Health and Safety Branch. See E. R. Woodcock et al., Session 6 of the International Conference on the Application of Computing Methods to Reactor Problems, ANL-7050 (May 1965).

6. J. T. Thomas, "Experimental and Calculated System Criticality," Table XV, Criticality Control of Fissile Materials, IAEA, Vienna (1966). 
Table 1. Unreflected Critical Arrays of Uranium Metal and Solution

\begin{tabular}{|c|c|c|c|c|c|c|c|}
\hline $\begin{array}{c}\text { Array } \\
\text { Description }\end{array}$ & $\begin{array}{l}\text { Unit } \\
\text { Av Mess } \\
(\mathrm{kg} U)\end{array}$ & $\begin{array}{l}\text { Descript } \\
\text { Diam } \\
\text { (cm) }\end{array}$ & $\begin{array}{l}\text { c } \\
\text { Height } \\
(\mathrm{cm})\end{array}$ & $\mathrm{n}_{1} \mathrm{n}_{2} \mathrm{n}_{3}$ & $\stackrel{\lambda}{\text { cim }} \underset{\text { From }}{i}$ & $\left.\mathrm{NB}_{\mathrm{N}}^{2} \cdot(2)\right]$ & $\begin{array}{l}\mathbf{k}_{\mathbf{e f f}} \\
(\mathrm{GEM})^{\alpha}\end{array}$ \\
\hline \multicolumn{8}{|c|}{ U(93.2) Metal Units } \\
\hline$A_{27}^{2}\{0 ; 2.007 ; 7 \cdot 767 ; 0.55\}$ & 10.484 & 11.509 & $5 \cdot 382$ & 333 & 1.86 & 0.670 & 1.0022 \\
\hline$A_{64}^{6}\{0 ; 3.952 ; 4.693 ; 0.61\}$ & 10.434 & 11.481 & 5.382 & 444 & 1.86 & 0.670 & 0.9937 \\
\hline$A_{27}^{4}\{0 ; 2.1 \div 36 ; 7.096 ; 0.96\}$ & 10.489 & 9.116 & 8.641 & 333 & 1.58 & 0.573 & 0.9919 \\
\hline$A_{64}^{4}(0 ; 4.625 ; 4.187 ; 0.96)^{b}$ & 10.487 & 9.116 & 8.641 & 444 & 1.58 & 0.573 & 1.0006 \\
\hline $\mathrm{B}_{8}^{1} \quad\{0 ; 0.902 ; 11.374 ; 0.73\}$ & 15.692 & 11.494 & 8.077 & 222 & 1.63 & 0.376 & 1.0349 \\
\hline $\mathrm{B}_{27}^{2}\{0 ; 4.204 ; 5.185 ; 0.78\}$ & 15.683 & 11.490 & 8.077 & 333 & 1.63 & 0.376 & 0.9836 \\
\hline$\{0 ; 2.248 ; 8.514 ; 0.95\}$ & 20.960 & 11.506 & 10.765 & 222 & 1.92 & 0.249 & 1.0047 \\
\hline$c_{27}^{3}\{0 ; 6.363 ; 3.827 ; 0.96\}$ & 20.877 & 11.484 & 10.765 & 333 & 1.92 & 0.249 & 0.9961 \\
\hline$D_{8}^{I} \quad\{0 ; 3.543 ; 6.806 ; 1.18\}$ & 26.218 & 11.509 & 13.459 & 222 & 2.56 & 0.179 & 0.9894 \\
\hline$D_{27}^{2}\{0 ; 8.484 ; 2 \cdot 980 ; 1.10\}$ & 26.113 & 11.486 & 13.459 & 333 & 2.56 & 0.179 & 0.9955 \\
\hline \multicolumn{8}{|c|}{ 5-liter $\mathrm{U}(92.6) \mathrm{O}_{2}\left(\mathrm{NO}_{3}\right)_{2}$ Solution Units } \\
\hline$F_{8}^{1} \quad\{0 ; 1.43 ; 0.214 ; 0.94\}$ & 2.074 & 20.32 & 19.05 & 222 & 0.510 & 0.124 & 1.0166 \\
\hline$F_{27}^{1}\{0 ; 6.48 ; 0.114 ; 0.95\}$ & 2.074 & 20.32 & 19.05 & 333 & 0.510 & 0.124 & 0.9979 \\
\hline $\mathrm{F}_{64}^{1}\{0 ; 10.67 ; 0.072 ; 0.96\}$ & 2.074 & 20.32 & 19.05 & 444 & 0.510 & 0.124 & 0.9926 \\
\hline$F_{125}^{1}\{0 ; 14.40 ; 0.052 ; 0.96\}$ & 2.074 & 20.32 & 19.05 & 555 & 0.510 & 0.124 & 1.0011 \\
\hline$\frac{2}{F_{8}} \quad\{0 ; 1.43 ; 0.144 ; 0.94\}$ & 1.395 & 20.32 & 19.05 & 222 & 0.335 & 0.126 & 0.9944 \\
\hline$\frac{2}{F_{27}}\{0 ; 6.40 ; 0.076 ; 0.95\}$ & 1.395 & 20.32 & 19.05 & 333 & 0.335 & 0.126 & 1.0017 \\
\hline \multicolumn{8}{|c|}{$\begin{array}{l}\text { a. Array description follows notation in Ref. 4, briefly, } \\
\qquad \text { unit designation }\left\{\begin{array}{l}\text { Refl. Surface } \\
\text { Thick }\end{array}\right. \\
\text { b. Estimated spacings. }\end{array}$} \\
\hline
\end{tabular}

d. GEM-3 Monte Carlo code was used to determine multiplication factor. 


\section{Systems of Large N}

Equation (2) and the values of $\lambda$ appearing in Table $I$ permit the critical conditions for systems of interest to nuclear safety specialists to be estimated. Presented in Table 2 are the results of applying Eq. (2) to the units of Table 1 . The arrays are three dimensional, cuboidal in shape, with an equal number of units along each of the three dimensions. The given $k$ values are the result of subjecting each of the estimated spacings to a Monte Carlo calculation.

The multiplication factors appearing in Table 2 are comparable to values given in Table 1 obtained for the experiments with these units. We also note that the array shape tends toward the optimum value of unity independent of the unit shape as $\mathrm{N}$ increases. This supports an earlier experimental observation ${ }^{4}$ that slight changes in unit shape result in smaller reactivity contributions to arrays than do slight changes in array shape.

The data of Tables 1 and 2 are presented graphically in Figs. 1 and 2. The metal systems shown in Fig. 1 display the effect of unit size on the critical number as a systematic decrease in average uranium density for increases in mass of a unit or more optimum unit shape. The slight variations in the slope of the lines for large $N$ is similar to the limits observed by Abbey $^{7}$ from Monte Carlo calculations on spherical units. He noted that for $N>64$ the values of the slope as a function of the spherical mass fell within the range 1.73 and 1.86. DTK calculations reported by Paxton $^{8}$ give a slope of 1.8 for the solution systems shown in Fig. 2.

The direct application of Eq. (2) to other than the existing experimental units is not possible. If the constant, $N_{N}^{2}$, is not known for an arbitrary unit, it may be possible to interpolate from the experimentally determined values in the case of a unit which is comparable to those used in experiments. One may also utilize Monte Carlo calculations to establish two "critical" configurations and then apply Eq. (2). It is stressed,

7. F. Abbey, "The Criticality of Interacting Arrays," Criticality Control of Fissi.Le Materials, IAEA, Vienna (1956).

8. H. C. Paxton, "Criticality Control in Operations with Fission Material," IA-3366, Los Alamos Scientific Laboratory (January 1966). 

Table 2. Critical Arrays Estimated by the $\mathrm{NB}_{\mathrm{N}}^{2}$ Method and
Computed Multiplication Factors.

\begin{tabular}{|c|c|c|c|}
\hline $\begin{array}{c}\text { Array } \\
\text { Description } \\
\end{array}$ & $\begin{array}{l}\mathrm{k}_{\text {eff }} \\
\text { (GEM) }\end{array}$ & $\begin{array}{c}\text { Array } \\
\text { Description }^{a} \\
\end{array}$ & $\begin{array}{r}k_{e f f} \\
(G E M) \\
\end{array}$ \\
\hline$A_{125}^{2}\{0 ; 5.599 ; 3.257 ; 0.64\}$ & -- & $c_{64}^{3} \quad\{0 ; 9.602 ; 2.306 ; 0.97\}$ & 0.9881 \\
\hline$A_{216}^{2}\{0 ; 7.060 ; 2.439 ; 0.67\}$ & 0.9875 & $c_{125}^{3}\{0 ; 12.365 ; 1.587 ; 0.97\}$ & - \\
\hline$A_{512}^{2}\{0 ; 9.619 ; 1.562 ; 0.71\}$ & 0.9978 & $c_{216}^{3}\{0 ; 14.818 ; 1.180 ; 0.97\}$ & 0.9937 \\
\hline$A_{1000}^{2}\{0 ; 11.852 ; 1.112 ; 0.74\}$ & 0.9916 & $c_{512}^{3}(0 ; 19.107 ; 0.747 ; 0.98\}$ & 1.0023 \\
\hline$A_{8000}^{2}\{0 ; 20.552 ; 0.3921 ; 0.81\}$ & -- & $\begin{array}{l}c_{1000}^{3}\{0 ; 22.841 ; 0.527 ; 0.98) \\
c_{8000}^{3}(0 ; 37.307 ; 0.182 ; 0.99\}\end{array}$ & $\begin{array}{r}0.9914 \\
--\end{array}$ \\
\hline$A_{64}^{4} \quad\{0 ; 4.625 ; 4.187 ; 0.97\}$ & 1.0006 & & \\
\hline$A_{125}^{4}\{0 ; 6.479 ; 2.852 ; 0.97\}$ & -- & $\mathrm{D}_{64}^{2} \quad\{0 ; 12.363 ; 1.778 ; 1.08\}$ & 1.0022 \\
\hline$A_{216}^{4}\{0 ; 8.118 ; 2.107 ; 0.97\}$ & 0.9767 & $D_{125}^{2}(0 ; 15.653 ; 1.218 ; 1.07\}$ & -- \\
\hline$A_{512}^{4}\{0 ; 10.973 ; 1.325 ; 0.98\}$ & 1.0074 & $D_{216}^{2}(0 ; 18.567 ; 0.903 ; 1.07\}$ & 0.9982 \\
\hline$A_{1000}^{4}\{0 ; 13.451 ; 0.932 ; 0.98\}$ & 0.9758 & $D_{512}^{2}\{0 ; 23.653 ; 0.570 ; 1.06\}$ & 0.9853 \\
\hline$A_{8000}^{4}\{0 ; 23.020 ; 0.321 ; 0.99\}$ & -- & $D_{1000}^{2}\{0 ; 28.074 ; 0.402 ; 1.05\}$ & 0.9800 \\
\hline & & $D_{8000}^{2}\{0 ; 45.181 ; 0.139 ; 1.03\}$ & - \\
\hline$B_{64}^{2}\{0 ; 6.815 ; 3.143 ; 0.81\}$ & 0.9983 & & \\
\hline$B_{125}^{2}\{0 ; 9.048 ; 2.171 ; 0.83\}$ & -- & $F_{216}^{I}\{0 ; 17.662 ; 0.0392 ; 0.97\}$ & 0.9802 \\
\hline$B_{216}^{2}\{0 ; 11.032 ; 1.618 ; 0.85\}$ & 1.0084 & $F_{512}^{I}\{0 ; 23.531 ; 0.0253 ; 0.97\}$ & 0.9791 \\
\hline$B_{512}^{2}\{0 ; 14.505 ; 1.028 ; 0.87\}$ & 1.0005 & $F_{1000}^{I}\{0 ; 28.691 ; 0.0181 ; 0.97\}$ & 1.0066 \\
\hline $\mathrm{B}_{1000}^{2}\{0 ; 17.531 ; 0.727 ; 0.88\}$ & 1.0202 & $F_{8000}^{I}\{0 ; 48.893 ; 0.0064 ; 0.98\}$ & -- \\
\hline$B_{8000}^{r}\{0 ; 29.276 ; 0.253 ; 0.92\}$ & 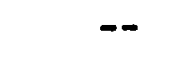 & & \\
\hline
\end{tabular}


Table 2. (Cont'd)

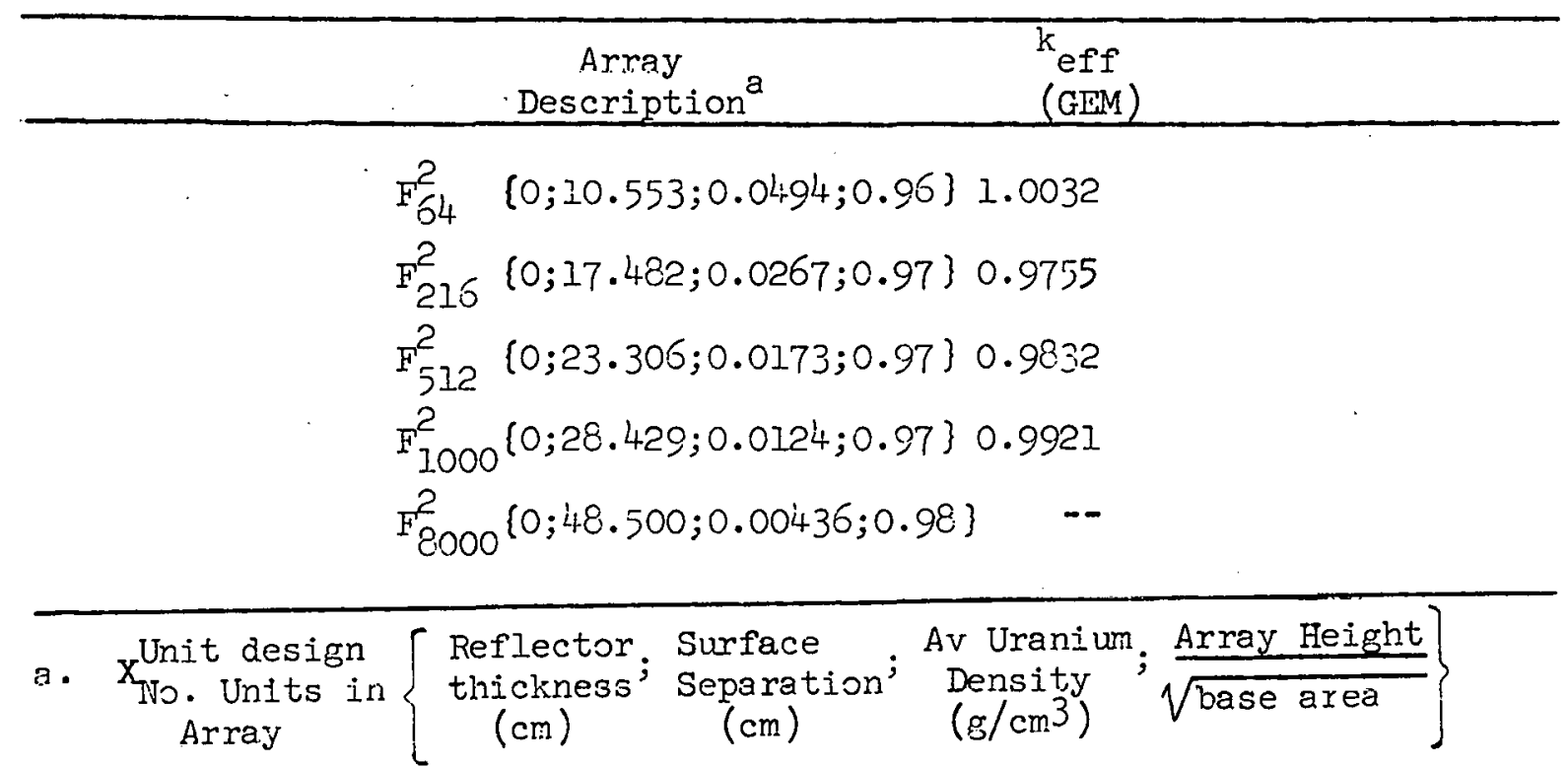

See Table 1 for unit description. 


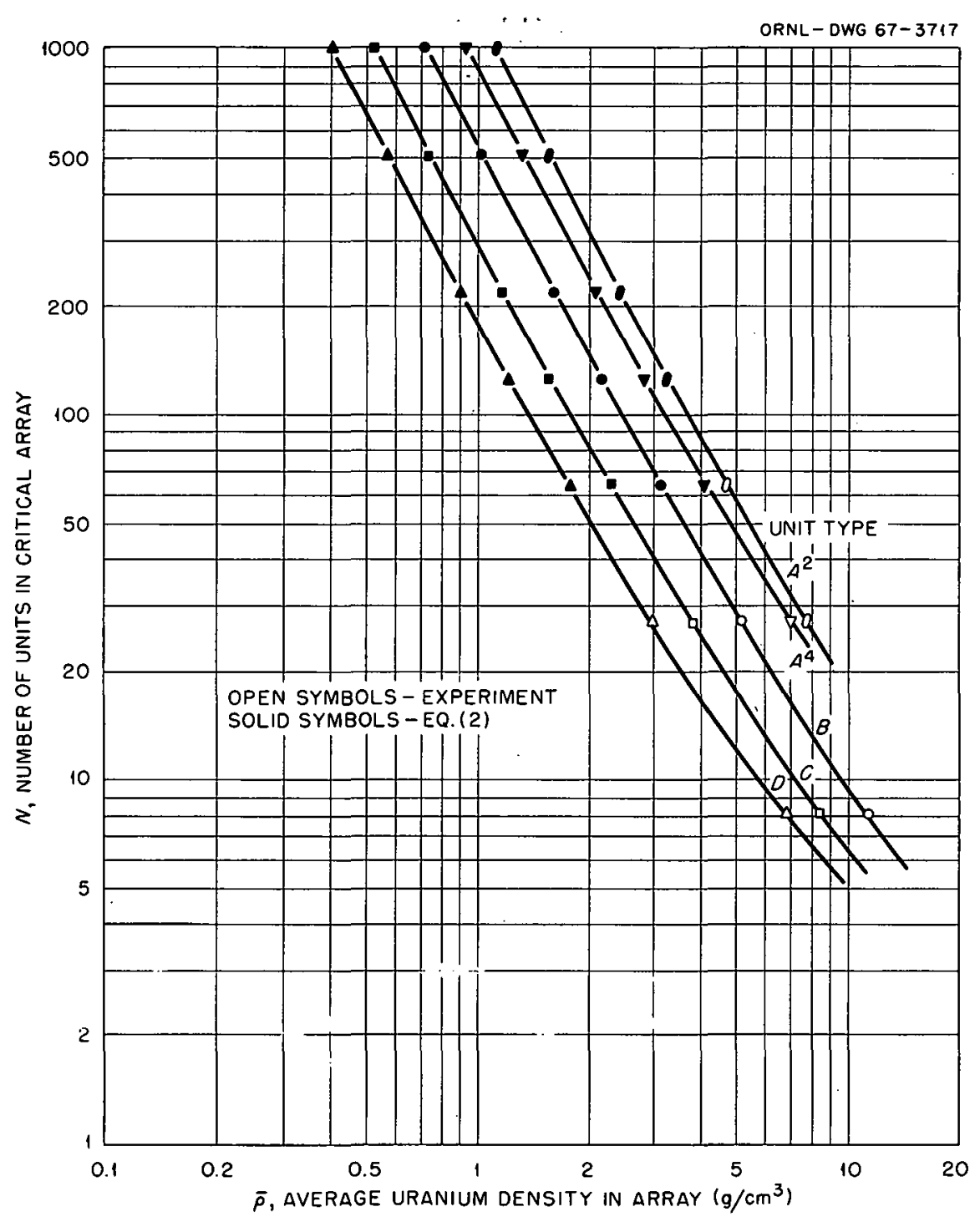

Fig. 1. Number of Units of U(93.2) Metal in Critical Arrays as a Function of the Average Uranium Density. (Experimental data of Table 1 and computed data of Table 2 are included.) 


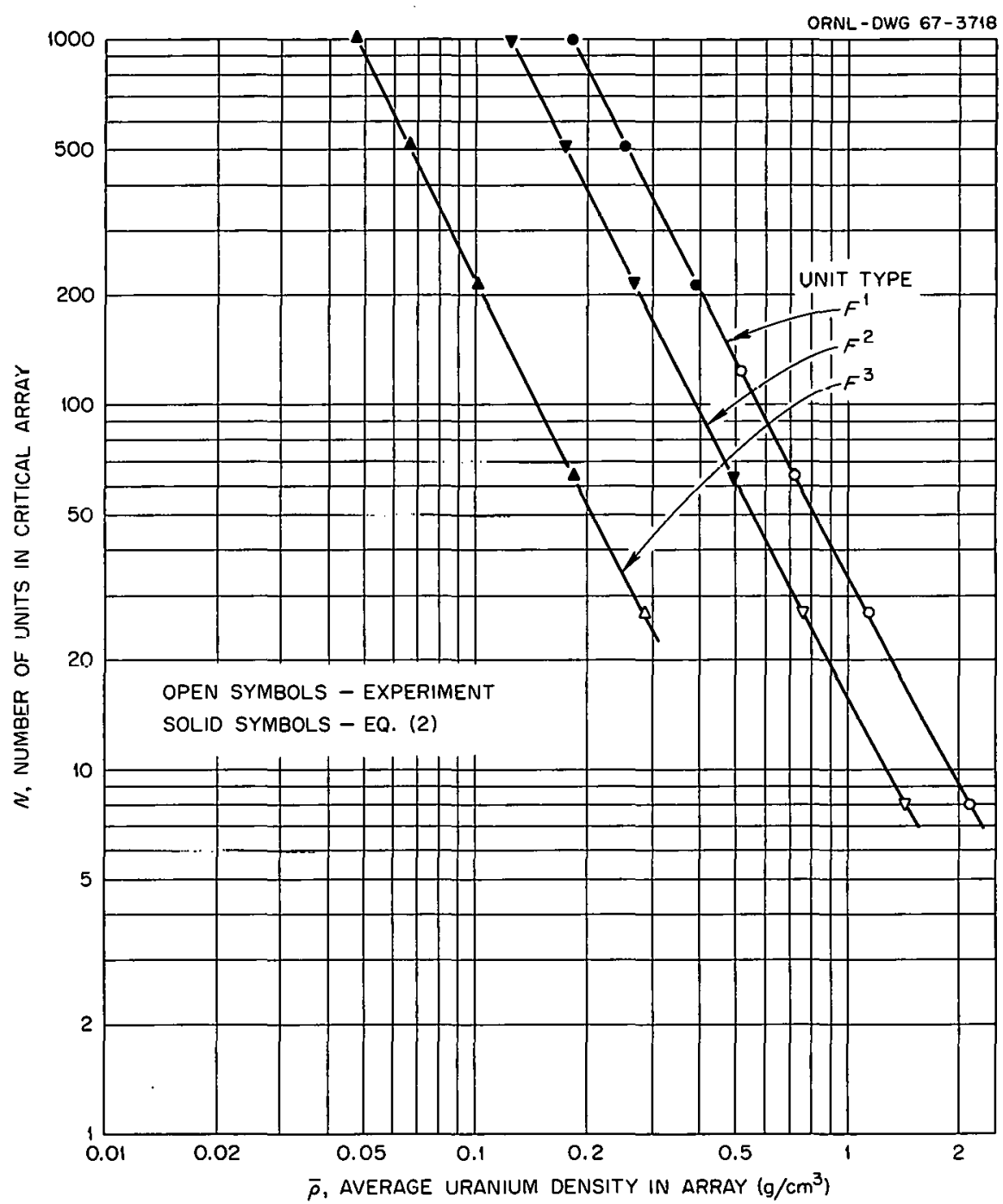

Fig. 2. Number Units of $\mathrm{U}(92.6) \mathrm{O}_{2}\left(\mathrm{NO}_{3}\right)_{2}$ Aqueous Solution in Critical Arrays as a Function of the Average Uraniun Density. (Experimental data of Táble 1 and computed data of Table 2 are included.) 
however, that one should demonstrate the ability of any proposed code to compute critical experiments with the same material composition as the units under question.

At the expense of the accuracy possible in the use of $\mathrm{Eq}$. (2), we derive in the following section a method which is an approximation to the results of Eq. (2) over a range of interest to criticality safety.

Density Analogue Representation

Let us accept the results of $\mathrm{Eq}$. (2) for large $\mathrm{N}$ as an extension of the experimental data listed in Table 1 . Let $\alpha$ be an index running through the units $x^{i}$ of Table 1 and define the quantity $\underline{\bar{K}}(\alpha)$ as the fraction of neutrons leaking from an N-unit critical array of $\alpha$ units, thus,

$$
\underline{\bar{K}}(\alpha)=\frac{N_{N}^{2}}{1+N B_{N}^{2}} .
$$

We begin by noting a productive correlation. of experimental data by means of this leakage parameter. Since the leakage fraction from every array of a particular $\alpha$ unit is assumed constant, it must be independent of the average uranium density of the system. We are led to ask, therefore, what is the relation between $\bar{K}(\alpha)$ and $\bar{\rho}$ (the unit mass dirided by the cell volume the unit occupies in the array) as a function of $\alpha$. The results for the cylindrical metal units are displayed in Fig. 3 where the leakage is shown as a function of the average uranium density for the different units.

With the exception of the eight unit arrays, the data for different $\alpha$ but equal $N$ appear to enjoy a linear relation including the point at the origin. We would like to relate the three quantities $\mathbb{N}, \underline{\bar{K}}(\alpha)$, and $\bar{\rho}$. This is most readily accomplished through the slope of the lines. Let $\theta$ be the angle made by the line for any given $N$ with the abscissa, then, expressed as a least squares fit 


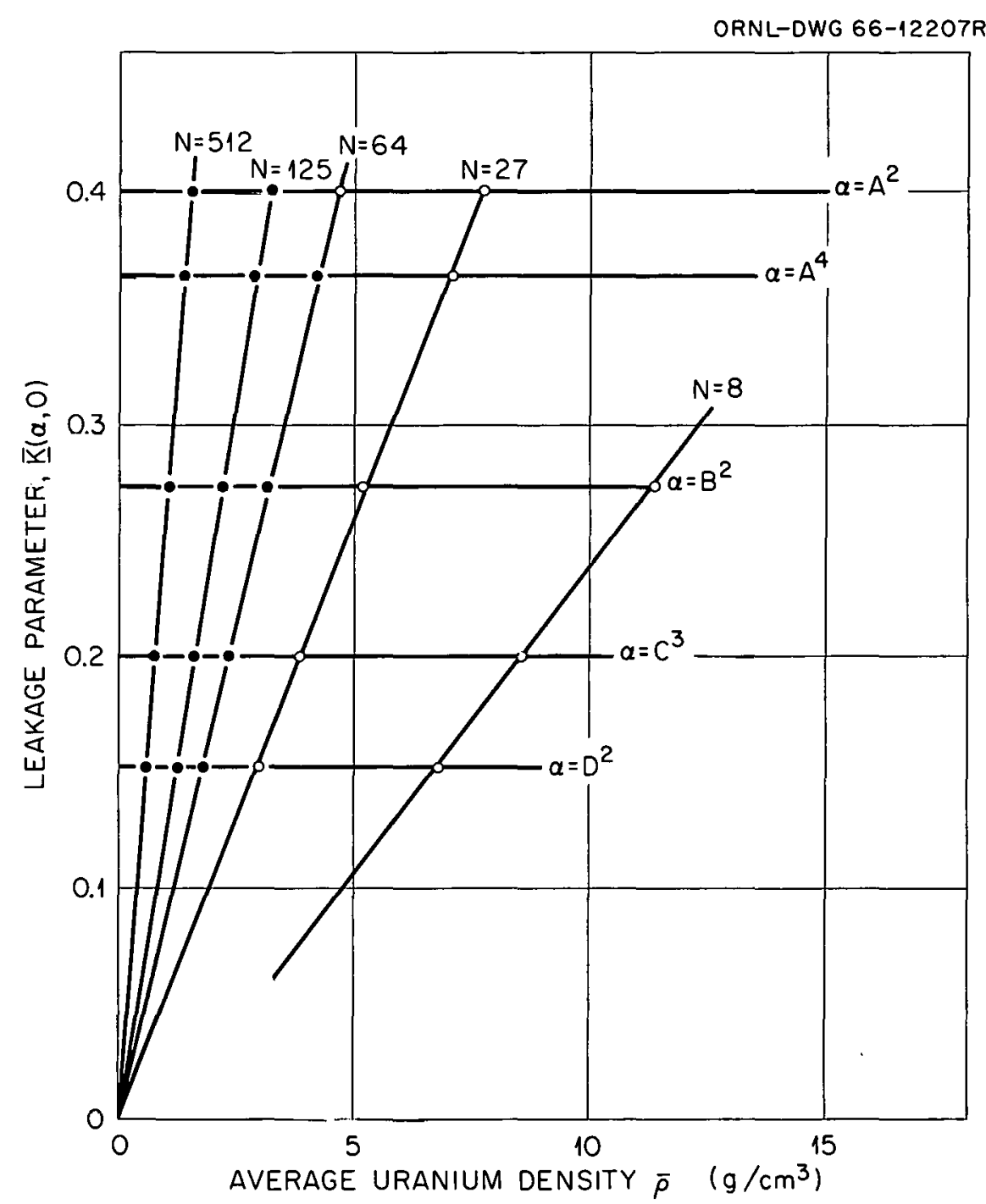

Fig. 3. The Leakage Parameter as a Function of the Average Uranium Density of Unreflected Critical Arrays of Cylindrical U(93) Metal Units. 


$$
\frac{\sum_{\alpha} \underline{\bar{K}}(\alpha)}{\sum_{\alpha} \bar{\rho}(\alpha)}=\tan \theta
$$

If we next plot $\mathbb{N}$ as a function of $\tan \theta$, we find the following relation subsists for $N \geq 27$ :

$$
N=A(\tan \theta)^{S}
$$

where $A$ and $s$ are constants independent of $\alpha$.

Combining Eqs. (5) and (6) we obtain an equation in the form of the density analogue representation

$$
N=A\left[\frac{\overline{\underline{K}}(\alpha)}{\bar{\rho}(\alpha)}\right]^{s} .
$$

The constants A and s of Eq. (6) or (7) are presented in Table 3 for the metal cylinders and for each of the solution units described in Table 1. Unlike the results for the uranium-metal cylinders, where the ${ }^{235_{\mathrm{U}}}$ concentration in the unit is constant and the unit size is changed, the two sets of constants $F^{1}$ and $F^{2}$ characterize materials having two separate and distinct spectra and, hence, the data for these different units cannot be represented by a single equation. It is expected, however, that each equation defined by the constants would adequately represent the criticality of different sized units at the same concentration.

It is emphasized that Eq. (7) is an approximation to the "experimental data" represented by Eq. (2). The distinction is clearly demonstrated in Fig. 4 where the results for the $B$ and $C$ units are presented from both Eq. (2) and Eq. (7). A further comparison is made by examining the ratio of the critical density from Eq. (7) to that determined from Eq. (2) for a given $\mathrm{N}$; this is presented in Table 4. The approximation may be considered good in the range from 27 to 8000 units. Outside this range, i.e., for $\mathrm{N}$ less than 27 or greater than 8000 units, Eq. (7) will yield densities that may be considered conservative. 
Table 3. The Constants of Eqs. (6) and (7) for the Various Units of Table 1 .

\begin{tabular}{ccc}
\hline Units & $\mathrm{A}\left(\mathrm{g} / \mathrm{cm}^{3}\right)^{\mathrm{s}}$ & $\mathrm{s}$ \\
Metal Cylinders & 6410.2 & 1.880 \\
$\mathrm{~F}^{1}$ & 27.804 & 1.974 \\
$\mathrm{~F}^{2}$ & 12.558 & 1.985 \\
\hline
\end{tabular}

Table 4. Ratio of Estimated Critical. Density $\bar{\rho}$ from Eq. (7) to that from Eq. (2) for Cylindrical U(93.2) Metal Units and $\mathrm{U}(92.6) \mathrm{O}_{2}\left(\mathrm{NO}_{3}\right)_{2}$ Solution Units

\begin{tabular}{ccccccccc}
\hline$N$ & $A^{2}$ & $A^{4}$ & Bype of Unit, $\alpha$ & & \\
\hline 27 & 0.9503 & 0.9424 & 0.9669 & 0.9567 & 0.9338 & 0.9959 & 0.9946 \\
64 & 0.9907 & 1.0091 & 1.0080 & 1.0034 & 0.9888 & 1.0025 & 0.9998 \\
125 & 0.9999 & 1.0376 & 1.0219 & 1.0211 & 1.0111 & 1.0046 & 1.0018 \\
216 & 0.9981 & 1.0500 & 1.0251 & 1.0269 & 1.0197 & 1.0048 & 1.0024 \\
349 & 0.9922 & 1.0545 & 1.0234 & 1.0272 & 1.0218 & 1.0043 & 1.0024 \\
512 & 0.9847 & 1.0550 & 1.0196 & 1.0249 & 1.0207 & 1.0035 & 1.0021 \\
$10^{3}$ & 0.9690 & 1.0502 & 1.0094 & 1.0167 & 1.0141 & 1.0013 & 1.0011 \\
$8 \times 10^{3}$ & 0.9091 & 1.0098 & 0.9611 & 0.9722 & 0.9719 & 0.9913 & 0.9958 \\
\hline
\end{tabular}




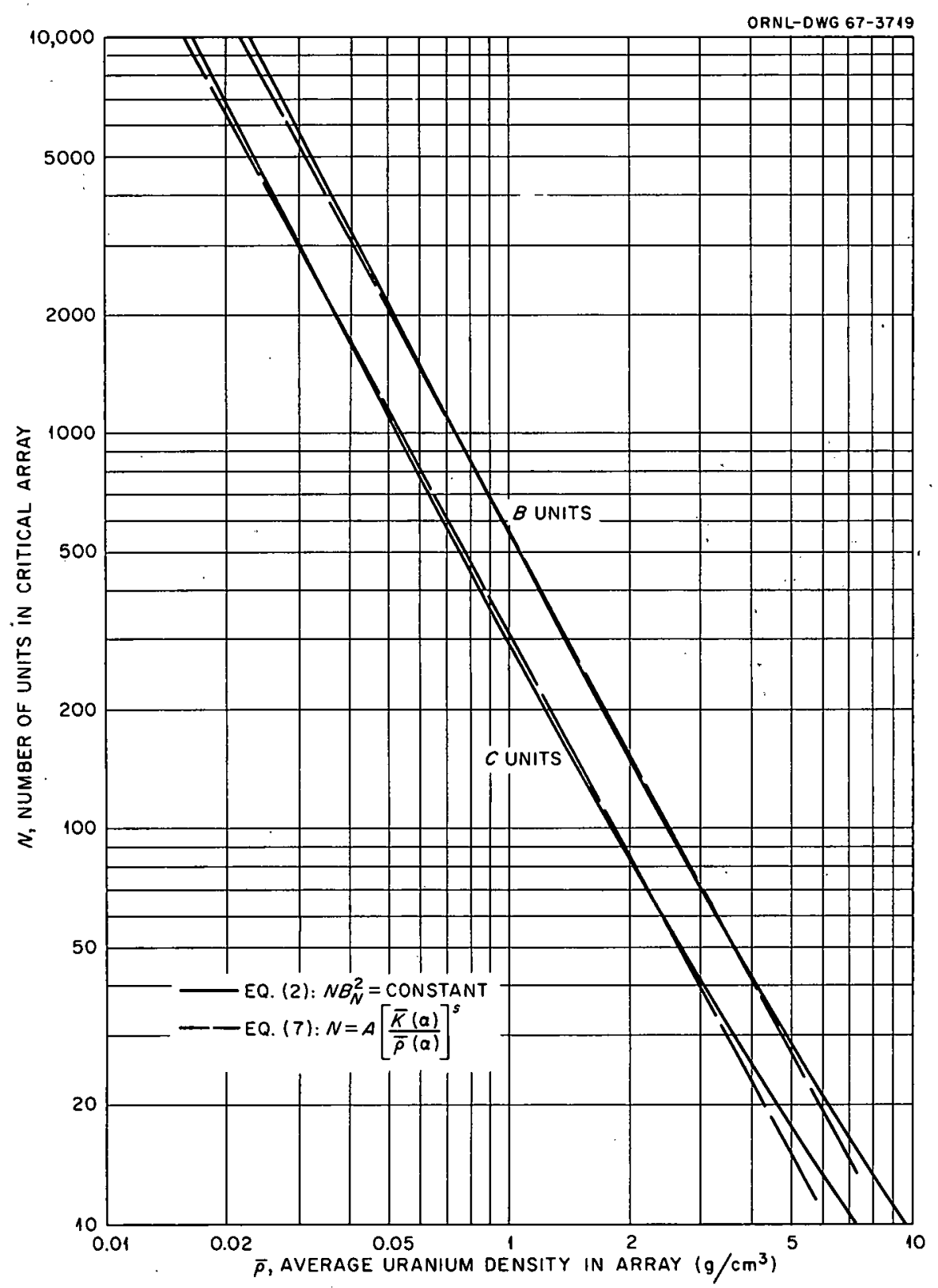

Fig. 4. Comparison of Predictions of the Dimensions of Critical Arrays by Eqs. (2) and (7). 
Thus far, we have concerned ourselves with the experimental units. It would be desirable to complete the generalization of $\mathrm{Eq}$. (7) for metal units by establishing a relation between $\overline{\underline{K}}(\alpha)$ and arbitrary cylindrical metal units. This can be accomplished in a number of ways, but the most useful, perhaps, is an expression of $\underline{\underline{K}}(\alpha)$ as a function of the surface-tovolume ratio of the unit. Listed in Table 5 are the $s / v$ ratio, the unit

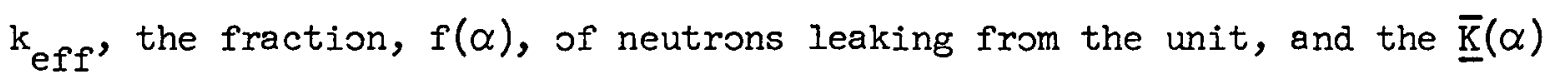
values determined for the experimental units $\alpha$. The following relations subsist for these data:

$$
f(\alpha)=1-0.177[\mathrm{~s} / \mathrm{v}]^{-0.959}
$$

and

$$
\frac{\overline{\bar{K}}(\alpha)}{f(\alpha)}=1.387 \frac{S}{V}-0.450 .
$$

The maximum percent error* in $\underline{\underline{K}}(\alpha)$, using Eqs. ( 8 ) and (9) for the experimental units, is 4.6; from Eq. (7), this produces an error in $N$ of $\sim 9 \%$.

Equations (7), (8), and (9) allow one to estimate the critical spacing for a given metal unit simply from its surface-to-volume ratio. This set of equations is valid for systems which are characterized by:

i. U(93) cylindrical metal units,

ii. Three dimensional cuboidal arrays of identical units,

iii. Unreflected and unmoderated systems, and

iv. $27 \leq \mathrm{N} \leq 8000$.

The application of Eqs. (2), (7), (8), and (9) is exemplified by estimating the critical densities and spacings for three arrays of specified units when an $N$ value of 216 is assumed. The $\underline{K}(\alpha)$ values as determined from Eqs. (8) and (9) give the constants to be used with Eqs. (2) and (7). The results are presented in Table 6; the values of $\lambda$ were estimates interpolated from values appearing in Table 1 since their influence is small and a slide rule was used throughout. The systems derived from

*The formulas are intended for "slide rule" accuracy. 
Table 5. Some Properties of the Cylindrical Metal Units.

\begin{tabular}{ccccc}
\hline Unit, ${ }^{a} \alpha$ & $\mathrm{S} / \mathrm{V}, \mathrm{cm}^{-1}$ & $\mathrm{k} \mathrm{eff}^{\mathrm{b}}$ & $\begin{array}{c}\text { Neutron Leakage } \\
\text { Fraction; }{ }^{\mathrm{b}(\alpha)}\end{array}$ & $\underline{\overline{\mathrm{K}}(\alpha)}$ \\
\hline $\mathrm{A}^{2}$ & 0.719 & 0.566 & 0.756 & 0.401 \\
$\mathrm{~A}^{4}$ & 0.670 & 0.595 & 0.744 & 0.364 \\
$\mathrm{~B}^{2}$ & 0.596 & 0.685 & 0.707 & 0.273 \\
$\mathrm{C}^{3}$ & 0.534 & 0.759 & 0.673 & 0.200 \\
$\mathrm{D}^{2}$ & 0.497 & 0.799 & 0.656 & 0.152 \\
\hline
\end{tabular}

a. See Table 1 for physical description of units.

b. Determined by Monte Carlo calculations.

Table 6. Comparison of $\bar{p}$ and $\delta$ as Determined by Eqs. (2) and (7) for Non-experimental Systems of 216 Units .

\begin{tabular}{|c|c|c|c|c|c|c|c|c|c|}
\hline \multirow[b]{2}{*}{$\alpha$} & \multirow{2}{*}{$\begin{array}{l}\text { Unit } \\
\text { Mass, } \\
\mathrm{kg} \mathrm{U}\end{array}$} & \multicolumn{2}{|c|}{ Description } & \multicolumn{4}{|c|}{$\mathrm{Eq} \cdot(2)$} & \multicolumn{2}{|c|}{ Eq. (7) } \\
\hline & & $\begin{array}{l}\text { Diam } \\
\mathrm{cm}\end{array}$ & $\begin{array}{c}\text { Height } \\
\mathrm{cm}\end{array}$ & $\begin{array}{c}\text { Est. } \\
\lambda \\
\mathrm{cm}\end{array}$ & $\xi \stackrel{\bar{\rho}}{\mathrm{U} / \mathrm{cm}^{3}}$ & $\begin{array}{r}\delta \\
\mathrm{cm}\end{array}$ & $\begin{array}{l}\text { Monte } \\
\text { Carlo } \\
k_{\text {eff }}\end{array}$ & $\begin{array}{l}\bar{\rho} \\
\mathrm{g} \mathrm{U} / \mathrm{cm}^{3}\end{array}$ & $\begin{array}{r}\delta \\
\mathrm{cm}\end{array}$ \\
\hline$E^{4}$ & 5.0 & 7.094 & 6.739 & $0.5 \ldots$ & 3.89 & 3.90 & 1.0060 & 3.63 & 4.15 \\
\hline$B^{5}$ & 15.68 & 10.388 & 9.869 & 1.7 & 1.48 & 11.73 & 0.9750 & 1.58 & 11.27 \\
\hline$c^{6}$ & 21.01 & 9.116 & 17.282 & 1.8 & 1.35 & 13.40 & 0.9971 & 1.35 & 13.39 \\
\hline
\end{tabular}


$\mathrm{Eq}(2)$ were calculated by the GEM Monte Carlo code and the resulting multiplication factors are reported in the table. The results of Eq. (2) appear reasonable while those of $\mathrm{Eq} .(7)$, which approximate the former, underestimate the critical density for the $5 \mathrm{~kg}$ unit, overestimate that for the $15 \mathrm{~kg}$ unit and agree in the case of the $21 \mathrm{~kg}$ unit. In summary, then, the results of $\mathrm{Eq} .(7)$ are within $12 \%$ of those from Eq. (2) for these units. The results for the $A^{2}$ unit appearing in Table 4 and those for the $5 \mathrm{~kg}$ unit of Table 6 suggest that as metal units become smaller the value of the slope used in Eq. (7) becomes larger, * approaching a value near 2. The range of values for the slope, 1.88 to 2.0 , however, is not significant for the purposes to which Eq. (7) should be applied, and a value of 1.88 will be conservative for small unit masses.

\section{PARAFFIN REFLECTED SYSTEMS}

The experimental investigation of critical reflected arrays beyond 64 components has not been possible because of limitations imposed by equipment and material requirements. The need for information concerning larger values of $\mathrm{N}$ in the low uranium density range becomes manifest when it is realized that factors for reflector addition to an array, as used in some safety specifications, are those determined in the experimental density range. Although it may be correct to assume the magnitude of the factor approaches a constant value as the density decreases, it is not clear from the present evidences of the reflector effectiveness that this will occur for other than extremely low average densities.

It is the intent here to apply the postulates of page 3 and Eqs. (2) and $(7)$ to the available experimental data on three dimensional cuboidal systems. Sumnarized in Table 7 are the experimental data ${ }^{4}$ for U(93.2) cylindrical metal units. Table 8 gives a summary of the data ${ }^{3}$ for the 5-liter units of uranyl nitrate solution. The units are those described

*This effect has been confirmed over larger ranges of $\mathbb{N}$ for the individual and collective units, 
Table 7. Critical Conditions for Regular Three Dimensional Arrays with Various Paraffin Reflectors

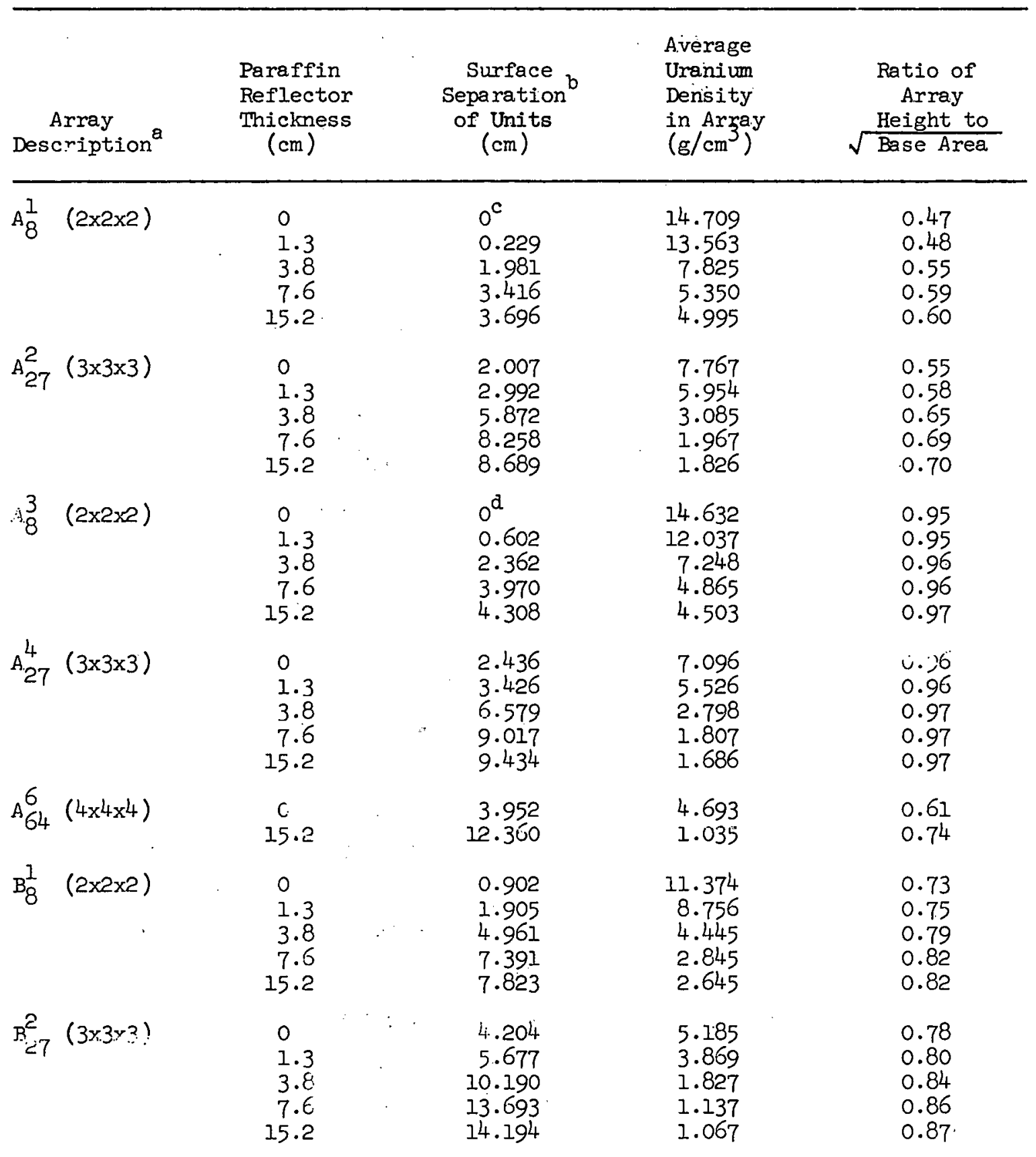


Table 7. Continued

\begin{tabular}{|c|c|c|c|c|}
\hline $\begin{array}{c}\text { Array } \\
\text { Description }^{a}\end{array}$ & $\begin{array}{l}\text { Paraffin } \\
\text { Reflector } \\
\text { Thickness } \\
\quad(\mathrm{cm})\end{array}$ & $\begin{array}{l}\text { Surface } \\
\text { Separation } \\
\text { of Units } \\
(\mathrm{cm})\end{array}$ & $\begin{array}{l}\text { Average } \\
\text { Uranium } \\
\text { Density } \\
\text { in Array } \\
\left(\mathrm{g} / \mathrm{cm}^{3}\right)\end{array}$ & $\begin{array}{c}\text { Ratio of } \\
\text { Array } \\
\text { Height to } \\
\sqrt{\text { Base Area }}\end{array}$ \\
\hline$c_{8}^{1} \quad(2 \times 2 \times 2)$ & 0 & 2.217 & 8.562 & 0.95 \\
\hline$c_{8}^{2} \quad(2 \times 2 \times 2)$ & $\begin{array}{l}0 \\
1.3 \\
2.5 \\
3.8 \\
7.6 \\
15.2\end{array}$ & $\begin{array}{r}2.248 \\
3.678 \\
5.710 \\
8.207 \\
1.1 .509 \\
11.986\end{array}$ & $\begin{array}{l}8.514 \\
6.295 \\
4.292 \\
2.843 \\
1.777 \\
1.669\end{array}$ & $\begin{array}{l}0.95 \\
0.95 \\
0.96 \\
0.96 \\
0.97 \\
0.97\end{array}$ \\
\hline$c_{27}^{3}(3 \times 3 \times 3)$ & $\begin{array}{r}0 \\
1.3 \\
3.8 \\
7.6 \\
15.2\end{array}$ & $\begin{array}{r}6.363 \\
8.574 \\
14.764 \\
18.720 \\
19.147\end{array}$ & $\begin{array}{l}3.827 \\
2.683 \\
1.187 \\
0.776 \\
0.74 .4 .\end{array}$ & $\begin{array}{l}0.96 \\
0.96 \\
0.97 \\
0.98 \\
0.98\end{array}$ \\
\hline $\mathrm{D}_{8}^{1} \quad(2 \times 2 \times 2)$ & $\begin{array}{r}0 \\
1.3 \\
3.8 \\
7.6 \\
15.2\end{array}$ & $\begin{array}{r}3.543 \\
5.423 \\
11.532 \\
15.697 \\
16.378\end{array}$ & $\begin{array}{l}6.806 \\
4.843 \\
1.976 \\
1.215 \\
1.130\end{array}$ & $\begin{array}{l}1.18 \\
1.12 \\
1.09 \\
1.07 \\
1.07\end{array}$ \\
\hline$D_{27}^{2}(3 \times 3 \times 3)$ & $\begin{array}{c}0 \\
1.3 \\
3.8 \\
7.6 \\
15.2\end{array}$ & $\begin{array}{r}8.494 \\
11.323 \\
19.606 \\
24.498 \\
24.991\end{array}$ & $\begin{array}{l}2.980 \\
2.025 \\
0.817 \\
0.531 \\
0.510\end{array}$ & $\begin{array}{l}1.10 \\
1.09 \\
1.06 \\
1.05 \\
1.05\end{array}$ \\
\hline
\end{tabular}

a. The letter and the superscript identify the average unit in the array described in Table 1; the subscript is the number of units in the array; the numbers in parentheses are the horizontal and vertical dimensions, respectively, of the array expreseed in number of units.

b. Errors on all surface separations are $\pm 0.013 \mathrm{~cm}$ for unreflected arrays and $\pm 0.026 \mathrm{~cm}$ Ior reflected arrays.

c. Array was subcritical with an apparent neutron source multiplication of $\sim 3$.

d. Array was subcritical with an apparent neutron source multiplication of $\sim 10$. 
Table 8. Critical Conditions for Regular Three Dimensional Arrays of $\mathrm{U}(92.6) \mathrm{O}_{2}\left(\mathrm{NO}_{3}\right)_{2}$-Five Liter Solution Units with Various Paraffin Reflectors

\begin{tabular}{|c|c|c|c|c|}
\hline $\begin{array}{c}\text { Array } \\
\text { Description }\end{array}$ & $\begin{array}{l}\text { Paraffin } \\
\text { Reflector } \\
\text { Thickriess } \\
\quad(\mathrm{cm})\end{array}$ & $\begin{array}{l}\text { Surface } \\
\text { Separation } \\
\text { of units } \\
(\mathrm{cm})\end{array}$ & $\begin{array}{l}\text { Average } \\
\text { Uranium } \\
\text { Density } \\
\text { in Array } \\
\left(\mathrm{g} / \mathrm{cm}^{3}\right)\end{array}$ & $\begin{array}{c}\text { Ratio of } \\
\text { Array } \\
\text { Height to } \\
\sqrt{\text { Base Area }}\end{array}$ \\
\hline$F_{8}^{1}(2 \times 2 \times 2)$ & $\begin{array}{r}0 \\
1.3 \\
3.8 \\
7.6 \\
15.2\end{array}$ & $\begin{array}{l}1.43 \\
3.28 \\
6.91 \\
8.48 \\
8.99\end{array}$ & $\begin{array}{l}0.214 \\
0.167 \\
0.108 \\
0.091 \\
0.087\end{array}$ & $\begin{array}{l}0.94 \\
0.95 \\
0.95 \\
0.96 \\
0.96\end{array}$ \\
\hline$F_{27}^{1}(3 \times 3 \times 3)$ & $\begin{array}{c}0 \\
1.3 \\
15.2\end{array}$ & $\begin{array}{r}6.48 \\
9.02 \\
16.53^{c}\end{array}$ & $\begin{array}{l}0.114 \\
0.086 \\
0.043\end{array}$ & $\begin{array}{l}0.95 \\
0.96 \\
0.96\end{array}$ \\
\hline$F_{64}^{1}(4 \times 4 \times 4)$ & 0 & 10.67 & 0.072 & 0.96 \\
\hline$F_{125}^{1}(5 \times 5 \times 5)$ & 0 & 14.40 & 0.052 & 0.96 \\
\hline$\frac{2}{F_{8}}(2 \times 2 \times 2)$ & $\stackrel{0}{11.4^{\mathrm{d}}}$ & $\begin{array}{l}1.43 \\
8.71\end{array}$ & $\begin{array}{l}0.144 \\
0.060\end{array}$ & $\begin{array}{l}0.94 \\
0.96\end{array}$ \\
\hline$F_{27}^{2}(3 \times 3 \times 3)$ & 0 & 6.40 & 0.077 & 0.95 \\
\hline
\end{tabular}

a. The letter and the superscript identify the average unit in the array described in Table 1; the subscript is the number of units in the array; the numbers in parentineses are the horizontal and vertical dimensions, respectively, of the array expressed in number of units.

$\mathrm{b}$. The uncertainty in the values of the separation is $\pm 0.13 \mathrm{~cm}$.

c. The separation was $16.91 \mathrm{~cm}$ where one face of the array was reflected by Plexiglas $15.2-\mathrm{cm}-$ thick.

d. The array was reflected on the bottom by $15.2-\mathrm{cm}$-thick paraffin. 
in Table 1. The ability of the Monte Carlo codes to compute these systems has been reported in Ref. 6 . We shall continue to use such calculations as a valuation of the methods when applied to reflected systems.

Clarification of the application and results of the equations will be made by introducing, where appropriate, the parameter $R$ for the reflector thickness about an array.

As in the case for unreflected systems, we use the experimental data for two critical systems with the same units to determine the constants $\lambda$ and $\mathrm{NB}_{\mathrm{N}}^{2}$ of $\mathrm{Eq}$. (2). A few represeniative determinations of the systems of Tables 7 and 8 for $R=15.2 \mathrm{~cm}$ are given in Table 9 where the calculated multiplication factors are also shown. Comparison of the $\lambda$-values with those of Table 1 for unreflected systems shows that larger values of $\lambda$ are necessary when a reflector is present as is the case for individual critical assemblies. ${ }^{2}$ Values of $\lambda$ for the intermediate reflector thicknesses lie between those for the two reflector conditions given in Tables 1 and 9.

\section{Reflected Systems of Large N}

We proceed to extend the data of Tables 7 and 8 to values of $N$ greater than 27 be means of $\mathrm{Eq}$. (2) and the constants of Table 9. Estimated critical conditions for the various units of Table 1 are presented in Table 10 along with a multiplication factor computed for a representative array from each group. With the exception of the B unit, the multiplication factors are comparable to those computed for the experiments of Table 9 . We will accept the results for the $B$ units as given.

The application of the postulates to the reflected systems of the experimental units is seen to yield reasonable results and, for nuclear safety purposes, we assume Eq. (2) adequately represents the criticality of large reflected systems. Considering the computed arrays as an extension of the experimental data, we proceed to derive a density analogue representation for thick-reflected systems as was done for the unreflected systems. 
Table 9. Representative values of the Constants $\lambda$ and $\mathrm{NB}^{2}$ for U(93) Metal and Solution Components in Thick Paraffin Reflected Systems.

\begin{tabular}{|c|c|c|c|}
\hline Array Description ${ }^{a}$ & $\begin{array}{c}\lambda \\
\mathrm{cm}\end{array}$ & $\mathrm{NB}_{\mathrm{N}}^{2}$ & $k^{b}$ \\
\hline$A_{64}^{6}(15.2 ; 12.360 ; 1.035 ; 0.74\}$ & 4.08 & 0.179 & 0.9815 \\
\hline$A_{8}^{3}\{15.2 ; 4.308 ; 4.503 ; 0.97\}$ & $3 \cdot 90$ & 0.168 & 1.0021 \\
\hline $\mathrm{B}_{8}^{1}(15 \cdot 2 ; 7 \cdot 823 ; 2.645 ; 0.82\}$ & 4.23 & 0.107 & 0.9869 \\
\hline$c_{27}^{3}\{15.2 ; 19.147 ; 0.744 ; 0.98\}$ & 3.45 & 0.0831 & $1.027^{*}$ \\
\hline$D_{27}^{2}\{15.2 ; 24.991 ; 0.510 ; 1.05\}$ & 3.94 & 0.0563 & $1.028 *$ \\
\hline$F_{8}^{1}\{15.2 ; 8.99 ; 0.087 ; 0.96\}$ & 1.89 & 0.0589 & $1.021 *$ \\
\hline$F_{27}^{l}\{15.2 ; 16.53 ; 0.043 ; 0.97\}$ & 1.89 & 0.0589 & 1.0056 \\
\hline
\end{tabular}

a. See Table 1 for an explanation of array description.

b. The starred values are computed by GEM-I and the unstarred values by GEM-3. 
Table 10. Critical Arrays Estimated by the $\mathrm{NB}^{2}$ Method and Representative Computed Multiplication Factors for the Units of Table 1.

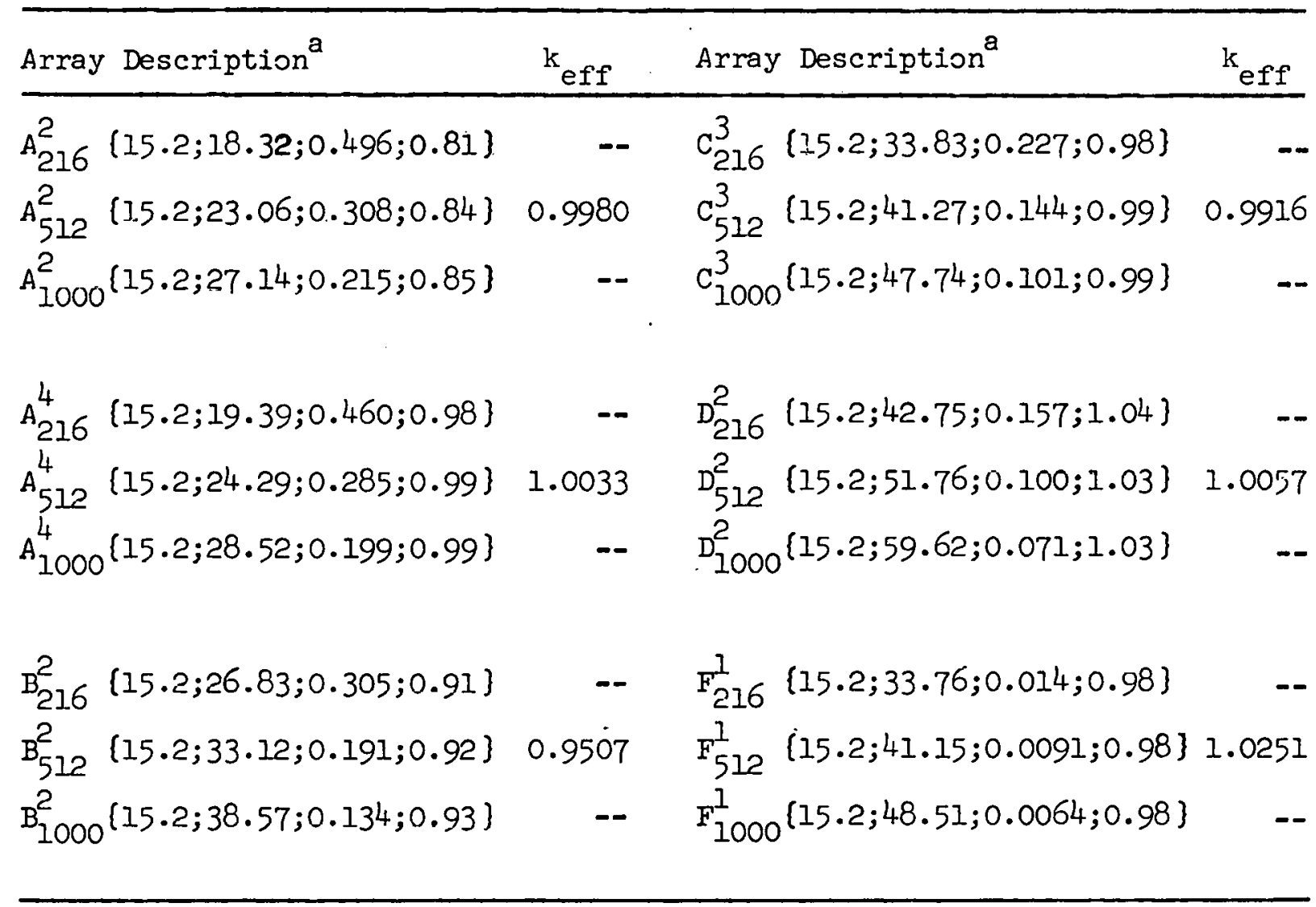

a. See Table 1 for array description. 
Density Analogue Representation With Reflector Present

Introducing the parameter $\mathrm{R}$ into $\mathrm{Eq}$. (7) to represent the thickness of reflector about an array we obtain

$$
N(R)=A(R)\left[\frac{\bar{K}(\alpha, R)}{\bar{\rho}(\alpha, R)}\right]^{s(R)}
$$

where Eq. (7) is now a special case for $R=0$. The values of $\underline{\bar{K}}(\alpha, R)$ as determined for the various reflector thicknesses and units of Tables 7 and 8 are given in Table 1l. $\bar{K}(\alpha, R), \bar{\rho}(\alpha, R)$ and Eqs. (5) and (6) provide the constants $A(R)$ and $s(R)$ given in Table 12. An index of the accuracy of $\mathrm{Eq}$. (10) in representing the results of $\mathrm{Eq}$. (2) is the ratio of the average density given by $\mathrm{Eq}$. (10) to that given by $\mathrm{Eq}$. (2). This comparison is made in Table 13 for an $R$ value of $15.2 \mathrm{~cm}$, and it may be seen that the critical densities are within a few percent of each other except for the $A^{4}$ unit where the maximum difference is about 7 percent. An error of $\pm 2 \%$ in $\bar{p}$ corresponds to an error in $N$ of $\pm 3.6 \%$. We are ignoring the $N=27$ and 8000 values since the straight line approximation to Eq...(2) should conservatively underestimate the critical densities for these values. If we were to not use the group averaged values of $A(R)$ and $s(R)$ for the metal cylinders, but rather their individual values, then the eiror in the approximation would be comparable to that for the $F^{I}$ units.

\section{Factors for Reflection}

Often it is convenient to know the ratio of the number of units in an unreflected critical array to that in a reflected critical array of the same average uranium density. The ratio is sometimes referred to as the reflection factor and is conveniently used when it is possible to more reliably estimate the critical conditions for an unreflected array. We shall show that such a factor is dependent on the unit size, density of fissionable material (or neutron energy spectrum), average density of the array, and the degree of array reflection. 
Table 11. Neutron Leakage Fraction for Reflected and Unreflected Critical Arrays of the Units in Table 1.

\begin{tabular}{llllll}
\hline Unit & \multicolumn{5}{c}{$\overline{\bar{K}}\left(\alpha, R^{*}\right)$} \\
$\alpha$ & $\underline{\bar{K}}(\alpha, 0)$ & $\underline{\bar{K}}(\alpha, 1.3)$ & $\overline{\underline{K}}(\alpha, 3.8)$ & $\underline{\bar{K}}(\alpha, 7.6)$ & $\underline{\underline{K}}(\alpha, 15.2)$ \\
\hline$A^{2}$ & 0.401 & 0.355 & 0.244 & 0.185 & 0.179 \\
$A^{4}$ & 0.364 & 0.338 & 0.224 & 0.174 & 0.168 \\
$B^{2}$ & 0.273 & 0.232 & 0.148 & 0.110 & 0.107 \\
$C^{3}$ & 0.200 & 0.159 & 0.0980 & 0.0778 & 0.0768 \\
$D^{2}$ & 0.152 & 0.118 & 0.0676 & 0.0535 & 0.0533 \\
$F^{1}$ & 0.111 & 0.0924 & 0.0695 & $\ldots$ & 0.0589 \\
\hline
\end{tabular}

* Reflector thickness in $\mathrm{cm}$.

Table 12. Values for the Constants $A(R)$ and $s(R)$ of Eq. (10) for the Units of Table $I$ as a Function of the Reflector Thickness, R.

\begin{tabular}{lccc}
\hline Units $\alpha$ & $R, c m$ & $A(R)$ & $s(R)$ \\
\hline$A^{2}, A^{4}, B^{2}, C^{3}$, or $D^{2}$ & 0 & 6410.1 & 1.880 \\
& 1.3 & 4832.9 & 1.877 \\
& 3.8 & 2299.6 & 1.817 \\
& 7.6 & 1578.1 & 1.802 \\
$F^{1}$ & 15.2 & 1503.8 & 1.805 \\
& 0 & 27.8 & 1.974 \\
& 1.3 & 22.7 & 1.960 \\
& 3.8 & 16.4 & 1.951 \\
& 15.2 & 14.0 & 1.938 \\
\hline
\end{tabular}


Table 13. Ratio of Estimated Critical Densities from Eq. (10) to that from Eq. (I) for the Units of Table 1 for $R=15.2 \mathrm{~cm}$.

\begin{tabular}{llllclll}
\hline$N$ & & \multicolumn{7}{c}{ Type of Unit, $\alpha$} & \\
\hline & $A^{2}$ & $A^{4}$ & $B^{2}$ & $C^{3}$ & $D^{2}$ & $F^{1}$ \\
\hline 27 & 0.9210 & 0.9250 & 0.9298 & 0.9565 & 0.9676 & 0.9776 \\
64 & 1.0037 & 1.0187 & 0.9967 & 0.9875 & 0.9936 & 0.9995 \\
125 & 1.0341 & 1.0567 & 1.0190 & 0.9919 & 0.9953 & 1.0076 \\
216 & 1.0431 & 1.0710 & 1.0254 & 0.9866 & 0.9883 & 1.0101 \\
512 & 1.0373 & 1.0717 & 1.0170 & 0.9672 & 0.9671 & 1.0088 \\
$10^{3}$ & 1.0215 & 1.0593 & 1.0006 & 0.94604 & 0.9451 & 1.0046 \\
$8 \times 10^{3}$ & 0.9423 & 0.9851 & 0.9233 & 0.8649 & 0.8627 & 0.9821 \\
\hline
\end{tabular}


Since the ratio of $N(O) / N(R)$ as obtained from $E q$. (2) does not differ appreciably from that of $\mathrm{Eq}$. (10) we shall utilize the latter because it is more tractable. Using Eq. (10) and maintaining the density as constant, i.e., $\bar{\rho}(\alpha, 0)=\bar{\rho}(\alpha, R)$ we find

$$
\frac{N(0)}{N(R)}=\frac{A(0)}{A(R)} \frac{\bar{K}(\alpha, 0)^{s(0)}}{\underline{\bar{K}}(\alpha, R)^{s(R)}} \bar{\rho}[s(R)-s(0)] .
$$

Define the quantity $c(\alpha, R)$ as

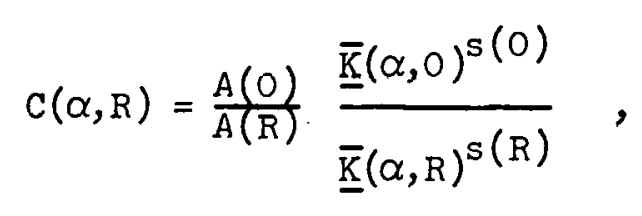

and define

$$
g(R) \equiv \frac{N(0)}{N(R)}=c(\alpha, R) \bar{\rho}^{-[s(0)-s(R)]} .
$$

This relation explicitly displays the dependence of the reflection factor $g(R)$ on density and implicitly, through $c(\alpha, R)$, the dependence on unit size and amount of array reflection. Considering the density dependence, we observe

$$
\begin{aligned}
\bar{\rho}^{-s^{\prime}(R)} & \geq 1 \text { for } \rho \leq 1 \\
& <1 \text { for } \rho>1,
\end{aligned}
$$

$$
\begin{aligned}
& \text { where } s^{\prime}(R)=s(0)-s(R) \text {. } \\
& \text { Thus, } g(R) \geq C(\alpha, R) \text { for } \bar{\rho} \leq 1 \\
& <\mathrm{c}(\alpha, \mathrm{R}) \text { for } \bar{\rho}>1 \text {. }
\end{aligned}
$$

Alternately stated, for systems with an average uranium density of less than unity, the constant $C(\alpha, R)$ will represent a lower bound to the factor $g(R)$; systems having $\bar{\rho}>1$ produce an upper bound for $g(R)$. The magnitude of the constant $C(\alpha, R)$ for the case of a 15.2-cm-thick paraffin reflector and 1 ts dependence on the unit size and density appear in Table 14. Tt. is emphasized that the actual factor $g(R)$ to be used in applications will be greater than those given if the average density is less 
Table 14. Lower Bounds for the Reflection Factors $g(R)$ and $g(\rho)$ as a Function of Unit Size and Density for a Value of $R=15.2 \mathrm{~cm}$.

\begin{tabular}{ccc}
\hline Unit, $\alpha$ & $C(\alpha, 15.2), \rho \leq 1$ & $C !(\alpha, 15.2)$, , fixed \\
\hline$A^{2}$ & 17.2 & 4.2 \\
$A^{4}$ & 15.7 & 4.1 \\
$B^{2}$ & 20.9 & 4.7 \\
$C^{3}$ & 21.1 & 4.8 \\
$D^{2}$ & 24.5 & 5.3 \\
$F^{1}$ & 6.3 & 2.6 \\
\hline
\end{tabular}


than unity. As an example, the $D^{2}$ units at a $\bar{\rho}$ value of $0.2 \mathrm{~g} \mathrm{U} / \mathrm{cm}^{3}$ (20 in. cube) gives $g(R) \sim 27$ which is greater than $C\left(D^{2}, 15.2\right)=24.5$

Also of interest is the case where the number of units is maintained and the addition of a reflector is compensated by a reduction in density $\bar{\rho}$. Again, using Eq. (10) with $N(O)=N(R)$ we obtain

$$
\frac{\bar{\rho}(\alpha, 0)}{\bar{\rho}(\alpha, R)}=\frac{A(0)^{l / s}(0)}{A(R)^{1 / s}(R)} \cdot \frac{\bar{K}(\alpha, 0)}{\underline{\bar{K}}(\alpha, R)} N \frac{s(0)-s(R)}{s(0)_{s}(R)} .
$$

Rewriting this as

$$
g(\dot{\rho}) \equiv \frac{\rho(\alpha, n)}{\rho(\alpha, R)}=C^{\prime}(\alpha, K) N^{\frac{s(0)-s(R)}{s(0) s(R)}}
$$

we see that $C^{\prime}(\alpha, R)$ represents a lower bound for $g(\bar{p})$ for all values of $\bar{\rho}$. Values for $C^{\prime}(\alpha, 15.2)$ are also presented in Table 14 .

The factors for reflection, $g(R)$ and $g(\bar{\rho})$, are valid for values of $N$ greater than 27 and less than 8000 units. This range is outside that investigated experimentally. One may use the experimental data and Eq. (2), to obtain more accurate values than can be had from a linear extrapolation of the data. Figure 5 gives such a representation for the two units $A^{2}$ and $C^{3}$; the points are experimental and the lines are from Eq. (2).

\section{REMARKS}

The fraction of neutrons leaking from a critical array of metal units, within the statistical uncertainty, is the same as that which leaks from a critical cylinder or sphere of metal, is a constant, and is independent of the size and number of pieces present. Of the two postulates upon which this work is founded, the first, that the neutron leakage fraction from different systems of the same units must be equal, is a special case of the above. The second, an instrument for the utilization of the first, gives an expression for the non-leakage fraction and gives numerical 


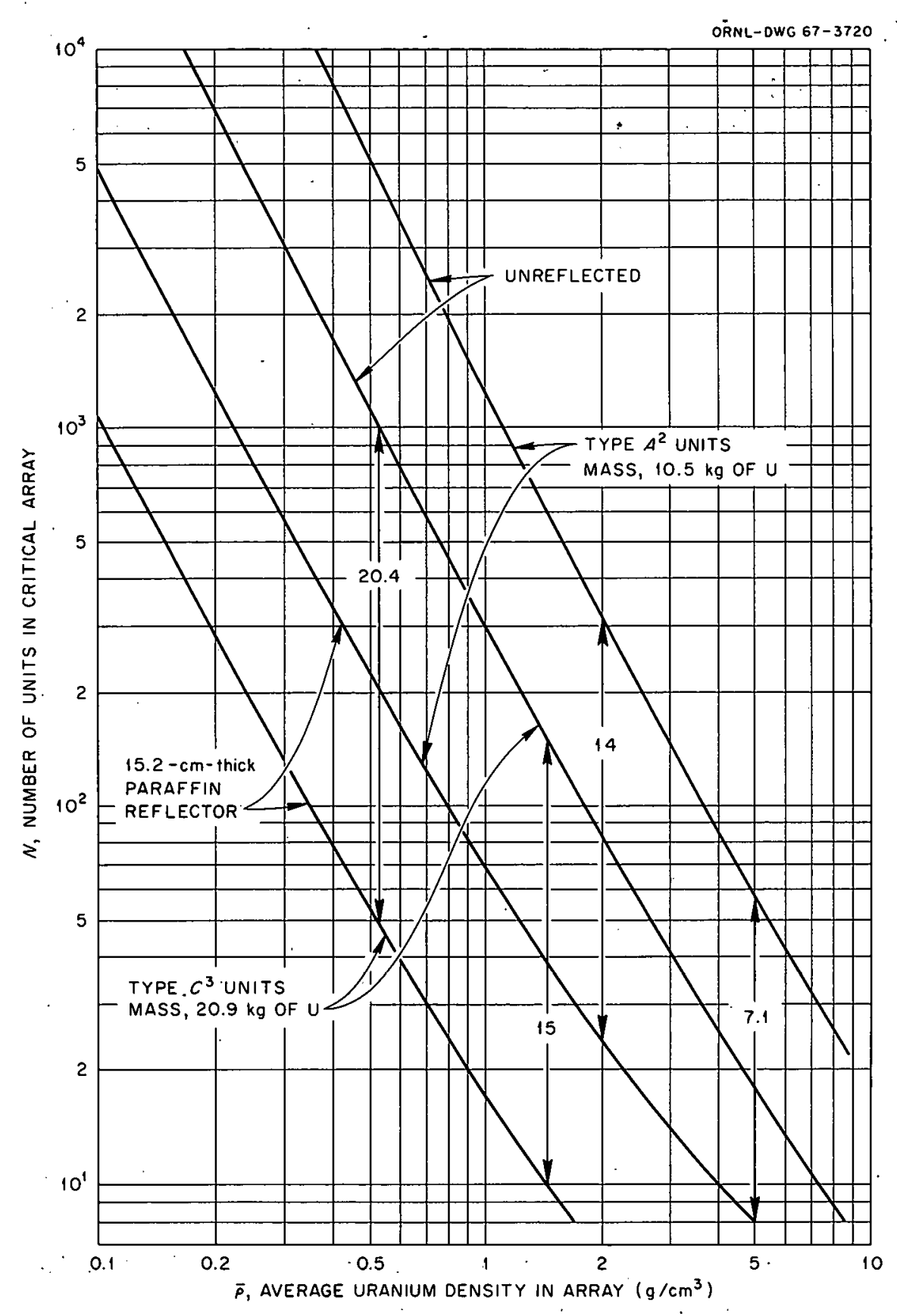

Fig. 5. Reflector Factors Obtained by Comparison of the Critical Dimensions of Unreflected and $15.2-\mathrm{cm}-$ Thick Paraffin Reflected Arrays of Cylindrical U(93) Metal Units. 
results quite distinct from the fractions obtained directly from Monte Carlo calculations. Judgement as to the reliability of the two postulates must be based on the results of their application to experimental and non-experimental systems and their valuation through Monte carlo calculations. Accepting such calculative techniques as a suitable criteria makes plausible the postulates for the purposes delineated herein.

It has been demonstrated that the equation $\mathrm{NB}_{\mathrm{N}}^{2}=$ constant provides more accurate estimates than its density analogue approximation. The accuracy of the latter, however, can be improved by using the constants $A(R)$ and $s(R)$ characteristic of a given unit rather than the average values derived for the material. The greatest usefulness of the density analogue representation is its ease of application in providing a rapid evaluation which facilitates separating problems into those which have no criticality hazard and those which must be examined with greater detail and accuracy.

The ratio of the number of units in an unreflected critical array to that when a reflector is present has been shown not to be constant but to exhibit a dependence upon unit material and size, average uranium density, and the amount of reflector present. The values for metal units are larger than any previously estimated for such systems in the density range considered here. Any proposed use of a reflection factor for nuclear safety specification should be consistent with the method used to estimate the critical conditions for a system.

The quantity $1-\bar{K}(\alpha, R)$ is similar to the reflection factor utilized in the GEM calculations. Under this guise one can regard $\{1-\underline{\bar{K}}(\alpha, R) / \underline{K}(\alpha, 0)\}$ as proportional to the albedo of a reflector about arrays of units. It may be deduced from the tabulated values of $\bar{K}(\alpha, R)$ that the fraction of neutrons returned by a thick paraffin reflector ranges from 0.55 to 0.65 for the metal cylinders and is about 0.47 for the $F^{l}$ solution units. The Monte Carlo calculations contained in this paper are for $10^{4}$ neutron histories and result in an accuracy of \pm 0.03 in $k$ at a 95 percent confidence interval. This accuracy was felt to be an adequate yardstick for nuclear safety specification and further expenditure of effort for improvement was not attempted. 


\section{ACKNOWLEDGEMENTS}

The sustaining interest of Drs. Dixon Callihan and H. C. Paxton has been very beneficial. - Their many helpful discussions and those with $\mathrm{Mr}$. D. R. Smith of Los Alamos are acknowledged gratefuily. To Messers. G. E. Whitesides and 0 . W. Hermann of the Computer Sciences Center at K-25 is due credit for the execution of the Monte Carlo calculations. 
INTERNAL DISTRIBUTION

$\begin{array}{ll}\text { 1- 3. } & \text { L. S. Abbott } \\ \text { 4. } & \text { R. G. Affel } \\ \text { 5. } & \text { F. T. Binford } \\ \text { 6. } & \text { F. R. Bruce } \\ \text { 7- 8. Dixon Callihan } \\ \text { 9. } & \text { R. Gwin } \\ \text { 10. } & \text { E. B. Johnson } \\ \text { 11. } & \text { W. H. Jordan } \\ \text { 12. F. Kertesz } \\ \text { 13. D. W. Magnuson } \\ \text { 14. } \\ \text { 15. C. Maienschein } \\ \text { I6. H. Marable } \\ \text { 17. J. T. Mihalczo } \\ \text { I8. P. Nichols } \\ \text { A. M. Perry }\end{array}$

19. S. J. Raffety

20. R. K. Reedy, Jr.

21-30. J. T. Thomas

31. J. W. Wachter

32. J. W. Webster

33. G. Dessauer (Consultant)

34. B. C. Diven (Consultant)

35. M. L. Goldberger (Consultant)

36. M. H. Kalos (Consultant)

37. L. V. Spencer (Consultant)

38-40. Central Research Library

41-42. ORNL Y-12 Technical Library Document Reference Section

43-342. Laboratory Records Department

343. Laboratory Records, ORNL R.C.

\section{EXTERNAL DISTRIBUTION}

34.4. F. W. Barclay, Whiteshell Nuclear Research Establishment, Pinawa, Manitoba, Canada

345. G. H. Bidinger, US AEC, Washington, D. C. 20545

346. P. A. Birkhofer, Institut Fur Mess - und Regelungstechnik, Technische Hochschule Munchen, Germany

347. C. I. Brown, Battelle Northwest Laboratory, P. O. Box 999, Richland, Wash. 99352

348. R. L. Brunnenmeyer, Bechtel Corp., 220 Bush Street, San Francisco, Calif. 94119

349. J. H. Chalmers, UKAEA Health and Safety Branch, Risley, England

350. F. R. Charlesworth, Ministry of Power, Thames House, Millbank, London, England

351. R. B. Chitwood, US AEC, Div. of Compliance, Washington, D. C. 20545

352. H. K. Clark, Savannah River Laboratory, Aiken, S. C. 29801

353. E. D. Clayton, Battelle Northwest Laboratory, P. 0. Box 999, Richland, Wash. 99352

354. D. F. Cronin, United Nuclear Corp., P. O. Box 1883, New Haven, Conn. 06500

355. J. T. Daniels, UKAEA Health and Safety Branch, Risley, England

356. C. Dawson, GE APED, San Jose, Calif. 95125

357. F. A. DeTroy, Metallurgie Hoboken, Olen (Antwerp), Belgium

358. K. W. Downes, Brookhaven National Lab., Upton, Long Island, N.Y. 11973

359. D. L. Dunaway, National Lead Co. of Ohio, P. O. Box 39158, Cincinnati, Ohio 45239

360. T. C. Engelder, Babcock and Wilcox Co., Lynchburg, Va. 24505

361. J. W. Flora, US AEC, Div. of Compliance, Denver, Colo. 8021.5

362. J. I. Forstner, Savannah Rlver Iaboratory, Aiken, S. C.2980I

363. J. K. Fox, Idaho Nuclear Corp., Idaho Falls, Idaho 83401

364. T. A. Fox, NASA-Lewis Research Center, 21000 Brookpark Road, Cleveland, Ohio 44100 
365. P. E. Hamel, Atomic Energy Control Board, Ottawa, Canada

366. G. E. Hansen, LASL, P. O. Box 1663, Los Alamos, N.M. 87544

367. H. F. Henry, Depauw University, Greencastle, Ind. 46135

368. D. L. Hetrick, University of Arizona, Tucson, Ariz. 85716

369. Information Research Center, Battelle Memorial Institute, 505 King Avenue, Columbus, Ohio 43201

370. W. Johnson, US AEC, Oak Ridge Operations Office, Oak Ridge, Tenn. 37830

371. Norman Ketzlach, Atomics International, P. 0. Box 309, Canoga Park, Calif. 91304

372. G. R. Kiel, Isochem, Inc., Richland, Wash. 99352

373. R. Kiyose, University of Tokyo, Tokyo, Japan

374. O. C. Kolar, Lawrence Radiation Laboratory, Livermore, Calif. 94551

375. R. C. Lane, UKAEA Atomic Weapons Research Establishment, Aldermaston, Berkshire, England

376-377. P. R. Lecorche, CEA, Service d'etudes de Criticite, Bat. 121, B.P. 2, 91 Gif s/Yvette (S\&O), France

378. W. B. Lewis, Phillips, Idaho Falls, Idaho 83401

379. Wesley Lewis, Nuclear Fuel Services, Inc., P. 0. Box 124, West Vailey, N. Y. 14171

380. C. D. Luke, US AEC, Washington, D. C. 20545

38I. A. J. Mallett, K-25

382. A. D. McGaugh, Westinghouse, Pittsburgh, Penn. 15122

383. J. E. McLaughlin, US AEC, 376 Hudson St., New York, N. Y. 10014

384. J. D. McLendon, Y-12

385. C. B. Mills, LASL, P. O. Box 1663, Los Alamos, N.M. 87544

386. Jean Moreau, Commissariat A I'Energie Atomique, Lederc Leaux, France

387. W. G. Morrison, Idaho Nuclear Corp., Idaho Falls, Idaho 83401

388. C. N. Nichols, UKAEA, Harwell, Didcot, Berks, England

389. H. C. Paxton, LASL, P. O. Box 1663, Los Alamos, N.M. 87544

390. William Pryor, US AEC, Oak Ridge Operations Office, Oak Ridge, Tenn. 37830

391. K. H. Puechl, Nuclear Materials and Equipment Corp., Apollo, Penn. 15613

392. Radiation Chemistry Data Center, University of Notre Dame; Notre Dame, Ind. 46556

393. S. L. Reese, Nuclear Safety Associates, 7735 Old Georgetown Road, Bethesda, Md. 20014

394. C. R. Richey, Battelle Northwest Laboratory, P. O. Box 999, Richland, Wash. 99352

395. Walter Schuller, GWK, Karlsruhe, Germany

396. C. L. Schuske, Rocky Flats Plant, Golden, Colorado 80401

397. Raffaele Semonetta, CNEN, Rome, Italy

398. D. R. Smith, LASL, P. O. Box 1663, Los Alamos, N.M. 87544

399. R. L. Stevenson, US AEC, Washington, D. C. 20545

400. W. R. Stratton, LASL, P. O. Box 1663, Los Alamos, N.M. 87544 
401. P. B. Suhr, Danish Atomic Energy Commission, Raskilde, Denmark

402. A. F. Thomas, UKAEA Atomic Weapons Research Establishment, Aldermaston, Berkshire, England

403. F. E. Woltz, Goodyear Atomic Corp., Piketon, Ohio 45661

404. D. P. Wood, US AEC, Sandia Base, Alubquerque, N.M. 87115

405. E. R. Woodcock, UKAEA Health and Safety Branch, Risley, England

406. B. J. Youngblood, US AEC, Div. of Compliance, 50 Seventh Street, Atlanta, Georgia 30300

407. I. F. Zartman, US AEC, Washington, D. C. 20545

408-624. Given distribution as shown in TID-4500 under Criticality Studies category 